\title{
Sex hormones, aging and cardiometabolic syndrome
}

\author{
Jessica L. Faulkner and Eric J. Belin de Chantemèle * (D)
}

\begin{abstract}
It is well documented that the metabolic syndrome predisposes patients to increased cardiovascular risk. Emerging data indicates that cardiovascular risk conferred by metabolic syndrome is highly dependent on sex and sex hormone status throughout the lifetime. Both male and female sex hormones, as well as sex chromosomes themselves, contribute to the development of obesity and intervene in the control of insulin homeostasis and blood pressure. Furthermore, men and women develop age-associated cardiometabolic risk in a sex-specific fashion in association with changes in these sex hormonal levels. Therefore, the current notion of the metabolic syndrome as a sex-independent diagnosis is antiquated, and novel studies and clinical trials utilizing these known sex differences in the development of metabolic dysregulation and cardiometabolic risk are warranted.
\end{abstract}

Keywords: Sex differences, Sex hormones, Obesity, Diabetes, Hypertension, Endothelial function, Aging

\section{Background}

The term "metabolic syndrome" is utilized today to refer to what has been formerly termed "insulin resistance syndrome," "cardiometabolic syndrome," or "syndrome X." Metabolic syndrome encompasses a collection of risk factors related to dysregulated energy, insulin, and lipid homeostasis that collectively confer additive cardiovascular risk in men and women. The clinical use of metabolic syndrome is as a predictor of cardiovascular disease risk, and its diagnosis is associated with an increased likelihood of coronary artery disease, myocardial infarction, and stroke $[1,2]$. The metabolic syndrome was first described in 1988 when it was noted that increased risk of coronary artery disease associated with insulin resistance commonly presents alongside other factors, notably dyslipidemia and hypertension, leading to a proposed collective "Syndrome $\mathrm{X}$ " of these risk factors for coronary artery disease [3]. The diagnosis of metabolic syndrome was then, and currently remains, a controversial topic due to discrepancies in criteria of inclusion and the individual risk afforded by those criteria. Emerging data of the contribution of obesity and central adiposity to insulin resistance risk evolved the diagnosis of metabolic syndrome to include central adiposity as

\footnotetext{
* Correspondence: ebelindechanteme@augusta.edu

* Correspondence: ebelindechanteme@augusta.edu

* Correspondence: ebelindechanteme@augusta.edu
Department of Medicine (Cardiology), Vascular Biology Center, Medical
College of Georgia at Augusta University, 1460 Laney Walker Blvd, Augusta, GA 30912, USA
}

(c) The Author(s). 2019 Open Access This article is distributed under the terms of the Creative Commons Attribution 4.0 International License (http://creativecommons.org/licenses/by/4.0/), which permits unrestricted use, distribution, and reproduction in any medium, provided you give appropriate credit to the original author(s) and the source, provide a link to the Creative Commons license, and indicate if changes were made. The Creative Commons Public Domain Dedication waiver (http://creativecommons.org/publicdomain/zero/1.0/) applies to the data made available in this article, unless otherwise stated. dictive factor in the development of cardiovascular diseases associated with metabolic dysregulation. As is
apparent from the sex-specificity in some of these criteria, eases associated with metabolic dysregulation. As is
apparent from the sex-specificity in some of these criteria,

a criteria, an important development as obesity continues to rise in prevalence. In 2009, a coalition of the National Heart, Lung, and Blood Institute, American Heart Association, World Heart Federation, International Atherosclerosis Society, and International Association for the Study of Obesity developed an overarching diagnostic criteria list for metabolic syndrome [4]. This consortium determined that at least 3 of the following diagnostic criteria must be met for diagnosis:

1. A waist circumference $>88 \mathrm{~cm}$ for women and $>$ $102 \mathrm{~cm}$ inches for men (in the USA, variable criteria for other countries) ${ }^{1}$

2. Circulating triglyceride levels above $150 \mathrm{mg} / \mathrm{dL}$ (or drug treatment to lower triglyceride levels)

3. Circulating HDL-C cholesterol below $50 \mathrm{mg} / \mathrm{dL}$ for women and $40 \mathrm{mg} / \mathrm{dL}$ for men (or drug treatment to elevate HDL-C levels)

4. Blood pressure above $130 / 85 \mathrm{mmHg}$ (or drug treatment to reduce elevated blood pressure)

5. Fasting blood glucose above $100 \mathrm{mg} / \mathrm{dL}$ (or drug treatment to reduce glycemia)

Importantly, sex is now emerging as a significant pre- 
the contribution of these factors to cardiovascular risk in men and women is not ubiquitous. Notably, sex differences are consistently emerging in rates of obesity and insulin resistance, factors that are primary contributors to the other diagnostic criteria of metabolic syndrome. In addition, aging presents a unique challenge to the prediction of cardiometabolic risk in men and women as both sex hormone-dependent and sex hormone-independent effects play various roles in the development of agingrelated cardiovascular diseases in men versus women. As the prevalence of metabolic syndrome is over $50 \%$ in both men and women over the age of 60 , with a sharper recent increase in this prevalence in women [7], understanding individualized metabolic syndrome development based on sex is of immense clinical importance to population-wide cardiovascular risk.

The presence of either obesity or insulin resistance in men and women increases risk for coronary heart disease, vascular dysfunction, myocardial infarction, and stroke [1]. It is also well established that abdominal obesity and insulin resistance in and of themselves are risk factors for dyslipidemia [8-10], which encompasses two other criteria of the metabolic syndrome, specifically hypertriglyceridemia and low levels of high-density lipoprotein (HDL)-C. These two types of dyslipidemias are known risk factors for atherosclerosis, coronary artery disease, and other cardiovascular events $[11,12]$. Triglyceride levels may be of particular importance to cardiovascular risk in obese men compared to women, as risk indices are increased in men compared to women for obesity [13] and insulin resistance [14]. However, despite that the prevalence of obesity and insulin resistance are not staving, improvements in dyslipidemia in both men and women have been dramatic population-wide in the last couple of decades, notably due to the increased prevalence of statins use [15]. In contrast, hypertension, the most prominent risk factor for cardiovascular events, is currently experiencing a rise in men and women, particularly young women [16, 17]. Alarmingly, rates of uncontrolled hypertension remain above $30 \%$ in both men and women, and may be rising in women, specifically $[16,18]$. These data collectively indicate that the most pressing studies needed to alleviate the burden of cardiometabolic risk are those to reduce the incidence of obesity and insulin resistance and those to better control blood pressure in at-risk men and women. The focus of this review is to evaluate sex differences and the role of sex hormones and chromosomes on adiposity, insulin resistance, and hypertension that support the need for a redirection of treatment strategies that take into account that adiposity, insulin resistance, and hypertension are the predominant present-day risk factors for cardiometabolic events, and treatment strategies need to be sex-specific to improve outcomes in patients with metabolic syndrome.

\section{Main text \\ Sex and adiposity \\ Obesity and visceral adiposity may be the primary factors underlying sex differences in prevalence of the metabolic syndrome}

Epidemiological data indicates that increased waist circumference is the most prevalent criteria of the metabolic syndrome in men and in women [19]; however, metabolic syndrome as diagnosed by the current criteria is more prevalent in women than men [20]. This sex discrepancy is likely due to sex differences in the rates of obesity and central adiposity between men and women. It is important to note that waist circumference and obesity are not synonymous; however, waist circumference is strongly associated with a body mass index $(B M I) \geq 30 \mathrm{~kg} / \mathrm{m}^{2}$ and is an additive, rather than exclusive, cardiovascular risk factor in obese patients [21, 22]. Several large-scale trials have demonstrated that rates of obesity are higher in women than men in the USA [2327] and worldwide [28]. In addition, there is a disparity in the severity of obesity between men and women, as the prevalence of class III obesity (BMI $>40 \mathrm{~kg} / \mathrm{m}^{2}$ ) is roughly $50 \%$ higher in women $[26,29,30]$. In association with rising rates of obesity, the prevalence of metabolic syndrome has risen more significantly in women of all age groups and races in the USA since the 1980s [31] indicating a cause-and-effect relationship of increasing $\mathrm{BMI}$ in women and prevalence of metabolic syndrome.

\section{Visceral adiposity in men may be regulated primarily by testosterone levels}

The sex-specific criteria for elevated waist circumference $(>102 \mathrm{~cm}$ for men vs. $>88 \mathrm{~cm}$ for women) make it slightly difficult to evaluate the effects of abdominal adiposity gram for gram between men and women. Mean waist circumference on average is higher in men compared to women $(\sim 95 \mathrm{~cm}$ in men vs. $\sim 83 \mathrm{~cm}$ in women in the Tromso Study) [32], but more women are diagnosed with elevated waist circumference than men. This is an important discrepancy as waist to hip ratio in men is more highly clinically correlative with myocardial infarction than obesity as a general factor [33], indicating that waist circumference improvement, i.e., visceral adiposity, may be of particular importance in men to prevent cardiometabolic risk rather than weight loss alone.

A sex-specific predisposition for abdominal, or visceral, adiposity in men may be due to adipose-regulating effects of testosterone. Although aging men do not experience a menopause-like dramatic decrease in sex hormone levels as experienced by women, testosterone 
levels decline steadily with age in men [34]. These declining testosterone levels are associated with elevated visceral adiposity observed in aging men [35], which may play a role in increased cardiovascular risk in aging men. Testosterone therapy has been shown to increase muscle mass/decrease fat mass in older men [36, 37]; therefore, long-term therapy may improve metabolic health by improving lean/fat mass ratio. However, dosing and efficacy remain a challenge to these therapies as many trials are conducted in men with very low testosterone levels and also the observation that testosterone efficacy to limit adipose growth may slow with age [38]. In association, testosterone therapy may preserve the ability of adipocytes to conserve lipids with age indicating that aging-associated adiposity may be an evolutionary mechanism in men to preserve both lean and adipose mass [39], which presents a challenge to overcoming obesity-associated adiposity.

Association studies of testosterone levels in men and women offer a paradox for determining its true effects on visceral adiposity independent of sex hormones. Low serum testosterone is associated with reduced subcutaneous, and increased abdominal, adiposity in men [4042], while high testosterone is associated with the same in women [43]. These data indicate that endogenous sex hormone- or chromosome-associated factors alter the effects of testosterone on adipogenesis in men and women. Whether testosterone acts to decrease abdominal adiposity independent of sex chromosomes is less clear, however. In women with androgen excess, a characteristic of polycystic ovarian syndrome (PCOS), estradiol + anti-androgen therapy is associated with reduced visceral adipose and higher lean mass in one study [44] and increased abdominal adiposity in another [45]. Therefore, further studies are needed to determine the true effect of anti-androgen therapy independent of estrogen on adipocyte deposition.

The mechanism(s) via which testosterone regulates adipose differentiation/deposition is likely an intraadipose mechanism. Male rats supplemented with dehydroepiandrosterone (DHEA), a precursor of sex steroid hormones, developed decreases in visceral (epididymal) adiposity in vivo in association with reduced stromal vascular growth within the tissue, and further, DHEA inhibited murine adipocyte proliferation in vitro [46]. These experimental effects are likely derived from the androgen receptor in adipose tissue itself as male mice with both global [47] and adipose-specific [48] androgen receptor deficiency exhibit increased weight gain and visceral adipose accumulation. The effects of estrogen on adipose deposition may not be efficacious in the presence of testosterone in males, in contrast to females. Increasing aromatase activity via transgenic overexpression of the aromatase enzyme specifically in white adipose of male mice, which subsequently increases estrogen/estrogen receptor activation in white adipose, did not have an effect to alter fat or lean mass in male mice, although they do report an improvement in insulin sensitivity and adipose inflammation in this model [49]. In contrast, global aromatase knockout in male mice decreases lean mass and impairs insulin sensitivity in male mice, indicating that the effects of aromatase and its subsequent changes on adipose tissue function remain unclear.

The role of lean mass as a measure of improved cardiometabolic risk in many of these studies may be of particular importance as several reports have indicated that lean mass is increased by testosterone therapy in men, even in the absence of a change in fat mass [50, 51], a physiological change that may be attributable to the known function of testosterone to increase muscle pluripotent cell differentiation [52]. Therefore, the potential for testosterone therapies to limit visceral adiposity in men requires further study into the mechanisms via which the hormone regulates adipose deposition on a cellular level.

\section{Female sex hormones promote subcutaneous adiposity}

Women are more predisposed to obesity compared to men, and in association, women of all ages demonstrate a higher body fat percentage compared to men [53]. Prior to menopause, women predominantly deposit adipose in subcutaneous depots rather than viscerally [54]. Many studies, particularly those of women prior and post-menopause, demonstrate that female sex hormones strongly regulate adipose locale in women. Changes in circulating sex hormone levels associated with menopause are associated with distinct changes in adipose distribution patterns, reverting to visceral accumulation and increasing the likelihood of elevations of waist circumference [55-62]. In the Study of Women's Health Across the Nation (SWAN) fat pattern study, it was demonstrated that low estrogen levels predicted visceral accumulation in women during and following menopause [43]. Female sex hormone effects on adipose deposition have also been reviewed in detail elsewhere [63].

In accordance with clinical studies, suppression of female sex hormones by ovariectomy in rodents increases gonadal (visceral), but not inguinal (subcutaneous) fat $[64,65]$. Whether the effects of estradiol on adipose tissues is a direct effect has been postulated. Both visceral and subcutaneous adipose [66, 67] tissues express estrogen receptors. Estrogen receptor- $\alpha$ deletion specifically in adipocytes increases fat pad weights of both subcutaneous and visceral adipose depots in male and female mice, indicating that estrogen receptors promote, but do not necessarily regulate, adipose generation within the tissue itself $[68,69]$. Furthermore, the fact that this was present in male and female mice indicates that intra- 
adipose effects of estrogen receptors to increase fat mass are not tied to sex-chromosomes, which indicates that sex hormone changes in menopause and their consequences to increase visceral adipose accumulation may involve other hormones, such as progesterone or testosterone. These studies also demonstrate that adipose dysfunction in response to adipose estrogen receptor deletion results in a systemic insulin-resistant phenotype, indicating a pronounced importance for these receptors for cardiometabolic health. The regulation of adipose function by adipose-specific estrogen receptors has been thoroughly reviewed elsewhere [70].

\section{Sex hormones in obesity-associated and obesity- independent insulin resistance}

Adiposity and obesity are heavily tied with insulin resistance, and increases in BMI on average correlate with higher fasting blood glucose across both sexes and at all ages. Similar to visceral adiposity, emerging evidence indicates that sex hormones play a significant role in insulin sensitivity both in lean and in obese men and women.

Studies indicate that elevated BMI produces a more pronounced insulin resistance phenotype in men than women [71]. Similar to visceral adiposity, hyperinsulinemia is also associated with low testosterone levels in men [40, 42]. Deficiency in androgen receptor signaling, both in male humans [72] and in rodents [47], conveys predisposition to insulin resistance. The insulin-sensitizing effects of testosterone have been attributed to androgen receptor activation in adipose and skeletal muscle promoting glucose uptake. Mice with global androgen receptor deficiency depict impaired glucose tolerance and lower phosphoinositide 3kinase (PI3K) expression in skeletal muscles [47]. Aging in men is associated with progressive declines in skeletal muscle glucose uptake, which may be improved by testosterone therapy [73]. Although testosterone therapy may have benefit to improve glucose handling, whether hormone therapy will be more efficacious than currently available glucose-lowering pharmaceutical agents is currently unknown and warrants investigation. In a recent study, testosterone therapy did not improve insulin sensitivity as well as metformin [74]. Therefore, testosterone therapy for insulin resistance patients may be best aligned with concurrent glucose-lowering drugs for maximum efficacy. A more comprehensive review of the role of androgens on mechanisms of insulin sensitivity has been published elsewhere [75].

Studies of female sex hormone actions on insulin resistance have been primarily focused on estrogens. Estradiol has been shown to have direct actions to increase glucose uptake in skeletal muscle and adipocytes as well as anti-inflammatory and anti-oxidant effects to improve insulin receptor function indirectly, as has been reviewed extensively elsewhere $[76,77]$. The most notable shift in insulin resistance in aging women occurs following menopause. Evidence is emerging that insulin resistance risk conferred from menopause in women may be alleviated by estradiol hormone replacement therapy, as has been reviewed [78]. Interestingly, in premenopausal women, phases of the menstrual cycle in which female sex hormones (estrogen and progesterone) are elevated are associated with an impairment in insulin sensitivity [79]. Therefore, the actions of progesterone may be antagonistic to those of estrogen on glucose uptake. This notion is supported by a study in which progesterone supplementation in female ovariectomized rats induced insulin resistance, while estrogen + progesterone combination did not [80]. These results may be attributed to the effects of progesterone to reduce glucose uptake in insulin responsive tissues, as progesterone supplementation has been shown to reduce glucose uptake markers in murine adipocytes [81]. With a distinct change in sex hormone status at menopause in women, the efficacy of glucose-lowering drugs in combination with hormone therapy (both oral contraceptive and post-menopausal supplement) is of paramount importance to determine optimum treatment strategies to improve glucose homeostasis in women across the lifespan.

\section{Hypertension is a sex-specific predictor of cardiometabolic risk}

Hypertension is a significant risk factor for cardiovascular disease mortality and a significant contributor to cardiovascular risk afforded by the metabolic syndrome $[82,83]$. Risk of hypertension is increased by the prior presentation of any of the other criteria: dyslipidemia, increased waist circumference, and insulin resistance [10, 84]. Therefore, hypertension is likely more of a "consequence" rather than an originating cause of metabolic syndrome.

Importantly, the measure of hypertension in metabolic syndrome patients provides a significant inference of cardiometabolic risk in patients as clinical evidence indicates that hypertension may be the strongest single predictor of cardiovascular events [82, 83, 85]. Currently, the rising rates of hypertension in both men and women are closely correlated with, and clinically attributable to, increasing rates of obesity and insulin resistance $[86,87]$. The metabolic syndrome criteria of $130 / 85 \mathrm{mmHg}$ as a minimum for inclusion were considered "pre-hypertension" patients until very recently. The American Heart Association in a conjoined effort with the American College of Cardiology re-determined diagnostic criteria for hypertension, in contrast to previous diagnostic criteria of 140/90 mmHg [88]. These lower thresholds of blood pressure reflect the cardiovascular risk brought on by even slight increases in systolic and diastolic pressure, making the control of hypertension in patients with 
metabolic syndrome of utmost clinical importance. In addition, vascular endothelial dysfunction, which is closely associated with hypertension, confers additional risk of potentiating metabolic dysfunction via contributing to vascular inflammation, vasoconstriction, and impaired glucose clearance in tissues [89]. Therefore, the cardiometabolic risk conferred by hypertension may also serve to further impair insulin resistance in metabolic syndrome patients.

The contribution of adipose tissue to hypertension is sex-specific and associated with adipose distribution. It has been demonstrated that a given mass of visceral adipose tissue is associated with a greater increase in muscle sympathetic nerve activity, a measure of systemic sympathetic tone, than the same mass of adipose of a different depot [90-92]. In association, sympathetic activation has been shown to be a significant player in the development of hypertension in obese men, but not in young women, as reviewed in detail elsewhere [93]. The contribution of sex hormones to adipose deposition is evident in that visceral adiposity increases in postmenopausal women [58-62], which is concordantly associated with increased sympathetic nervous system tone in postmenopausal women [94]. In addition, sympathetic activation increases in both men [95] and women [96] with aging, implicating these measures gain importance as men and women age; however, mechanisms of cardiometabolic hypertension risk in younger women remain more elusive.

Overall, hypertension rates are higher in men than in women prior to ages associated with menopause; however, an alarming recent clinical trend indicates that hypertension prevalence is increasing in young women [17]. This increase is likely attributable to the strong association of obesity, insulin resistance, and hypertension in premenopausal women [97], the presentation of which negates cardiovascular protection that has been attributed to female sex hormones in young women $[98,99]$. With the role of sympathetic tone in blood pressure control males and postmenopausal females well versed in the current literature, the question remains of mechanisms controlling blood pressure in young females with metabolic syndrome. Emerging data indicates the aldosterone-mineralocorticoid receptor axis may provide a mechanistic link between obesity and hypertension in young women. Clinical data indicates that mineralocorticoid receptor antagonism may be more efficacious for blood pressure reduction in women compared to men, albeit not in an age-adjusted population [100]. Furthermore, aldosterone levels are increased in closer association with BMI in women compared to men [101]. Recent studies from our group demonstrate that leptin increases adrenal aldosterone production, and increases serum aldosterone levels, in young obese female rodents which underlies the development of endothelial dysfunction and hypertension [102, 103]. A more detailed synopsis of this potential pathway for leptin-induced aldosteronemediated hypertension risk in premenopausal women has been reviewed by the authors previously $[104,105]$.

\section{Cardiometabolic risk may be increased by dissociation of sex chromosome complement to sex hormones}

Sex chromosome complement to sex hormones may play a significant role in cardiometabolic risk. Experimentally, mouse models in which sex chromosome complement and sex hormones may be dissociated provide a promising avenue to begin to answer these questions. The 4-core genotype mouse model allows for the differentiation of effects of sex chromosomes from that of sex hormones by genetic modification to the Sry-maledetermining region of the $\mathrm{Y}$ chromosome in males to create $\mathrm{XY}$ females and XX males. Independent of female or male sex hormones, mice with two $\mathrm{X}$ chromosomes developed higher body adiposity, but similar distribution patterns to females with intact sex hormone production, which was accompanied by increased insulin resistance and dyslipidemia [106]. In the same study, XY chromosome complement in mice was associated with elevated gonadal adipose weight [106], indicating a role for the non-Sry (testes-determining) region of the $\mathrm{Y}$ chromosome in the regulation of adipocyte mass and distribution. In addition, independent of alterations in adipose tissue mass, sex chromosome complement of XX is associated with a potentiation of angiotensin II-induced hypertension in the absence of female sex hormones [107]. This study indicates that changes in female sex hormones in women may have a more pronounced effect directly on blood pressure control in women, a factor to be considered in obese women with hypertension. Therefore, both sex chromosome complement and hormone status play a role in cardiometabolic consequences of adiposity, which strengthens the need for datainspired therapeutic regimens based on both of these aspects of sex in metabolic syndrome patients.

\section{Efficacy of sex hormone therapy for cardiometabolic risk prevention is dependent on dosing factors: evidence from postmenopausal women and transgender therapies}

It would be convenient to say that hormone supplement therapy to aging men and women with reduced testosterone or estradiol levels is the key to reducing their likelihood of metabolic syndrome-associated cardiovascular events. This complication is apparent in data from the Women's Health Initiative, in which equine estrogens were administered alone or in combination with medroxyprogesterone acetate to over 100,000 postmenopausal women. The results from this study, which overall determined an increased risk for thromboembolytic events and coronary heart disease in response to hormone therapy, 
resulted in a large-scale clinical brake on postmenopausal hormone replacement therapy [108, 109]. However, since the release of these conclusions, a number of studies have emerged demonstrating a potential benefit for controlled postmenopausal estrogen therapies, with an added focus on dosing, formulation, and menopausal status at initial administration, which has been reviewed elsewhere [110].

Studies of hormone therapy in transgender individuals offer a cohort in which to determine a cause and effect relationship of sex hormones to cardiometabolic risk as the endogenous sex hormones are usually suppressed simultaneously to hormone supplementation. The potential benefit to these studies is primarily the ability to render effects attributable to the hormones themselves independent of sex chromosomal effects in a human population. However, it is important to note that dosing and hormone regimens as well as adherence is highly variable in these studies and the results are therefore difficult to extrapolate in certain studies, in addition to the confounding factor of the developmental exposure to the patients' endogenous sex hormones for variable amounts of time. However, these patients do shed some light into the potential effects that hormone therapies have on the characteristics of metabolic syndrome.

Studies have shown that, overall, risk of myocardial infarction is increased in transgender-identifying individuals, both male and female [111], and that gender reassignment surgery and hormone therapies are associated with a 2+-fold increase in odds risk for death by cardiovascular diseases [112]. Data in transgender men to women transition indicate that estrogen therapy combined with an antiandrogen conveys an increased risk of cardiovascular disease-related death [113]. However, other data on estrogen therapy and cardiovascular risk do not convey similar associations [114], and in addition, these studies do not necessarily account for other cardiovascular risk factors that may be more prevalent among transgender individuals, such as a higher prevalence of smoking [115]. However, with the known cardiovascular effects of sex hormones and the data in mice conferred by genomic sex chromosome complement models, it is likely that estrogen and testosterone may confer cardiometabolic protection only when accompanied by a certain sex chromosome complement. However, dosing is notably inconsistent throughout most studies of transgender hormone therapy, rendering a generalization of the role of hormone therapies in cardiovascular risk difficult to determine at present. A comprehensive review of studies of hormone therapy and associated cardiovascular factors has been published previously [114]. Collectively, the presentation of various outcomes of cardiometabolic risk in these patients undergoing hormone replacement therapies highlights the importance of continued study into efficacious dosing and formulations of hormone therapies both in cisgender and transgender patients.

\section{Conclusion}

Sex-discrepant prevalence of adiposity and insulin resistance render differences in cardiometabolic risk between men and women. The promise of therapies for adiposity and insulin resistance may include sex hormone supplements; however, many strides are needed to determine the appropriate treatment dosages and outcomes and consideration of chromosome complement effects. Future trials, some of which are currently ongoing, will continue to provide evidence for the appropriate determination of the effects of individual sex hormones on metabolic function in men and women at all ages [116]. In addition, with the advent of statins for the control of dyslipidemia, prevention of hypertension risk is a crucial missing link to improvement of cardiometabolic risk.

\section{Endnotes}

${ }^{1}$ Importantly, it has been suggested that ethnicityspecific criteria for waist circumference be established to optimally predict cardiometabolic risk $[5,6]$, although this is not currently included in the metabolic syndrome diagnosis.

\section{Abbreviations}

BMI: Body mass index; DHEA: Dehydroepiandrosterone; HDL: High-density lipolipids; PCOS: Polycystic ovarian syndrome; PI3K: Phosphoinositide 3-kinase

\section{Acknowledgements}

Not applicable

\section{Authors' contributions}

JLF and EJBdC contributed to the drafting and revision of the manuscript. Both authors read and approved the final manuscript.

Funding

This work was supported by NIH 1R01HL130301-01 to EbdC and NIH 5F32HL136191-02 to JLF.

Availability of data and materials

Not applicable

Ethics approval and consent to participate

Not applicable

Consent for publication

Not applicable

Competing interests

The authors declare that they have no competing interests.

Received: 12 February 2019 Accepted: 14 June 2019

Published online: 01 July 2019

\section{References}

1. Xanthakis V, Sung JH, Samdarshi TE, Hill AN, Musani SK, Sims M, et al. Relations between subclinical disease markers and type 2 diabetes, metabolic syndrome, and incident cardiovascular disease: the Jackson Heart Study. Diabetes Care. 2015;38(6):1082-8. 
2. Zidi W, Allal-Elasmi M, Zayani Y, Zaroui A, Guizani I, Feki M, et al. Metabolic syndrome, independent predictor for coronary artery disease. Clin Lab. 2015, 61(10):1545-52.

3. Reaven GM. Banting lecture 1988. Role of insulin resistance in human disease. Diabetes. 1988;37(12):1595-607.

4. Alberti KG, Eckel RH, Grundy SM, Zimmet PZ, Cleeman Jl, Donato KA, et al. Harmonizing the metabolic syndrome: a joint interim statement of the International Diabetes Federation Task Force on Epidemiology and Prevention; National Heart, Lung, and Blood Institute; American Heart Association; World Heart Federation; International Atherosclerosis Society; and International Association for the Study of Obesity. Circulation. 2009;120(16):1640-5.

5. Katzmarzyk PT, Bray GA, Greenway FL, Johnson WD, Newton RL Jr, Ravussin $\mathrm{E}$, et al. Ethnic-specific BMl and waist circumference thresholds. Obesity (Silver Spring). 2011;19(6):1272-8,

6. Ntuk UE, Gill JM, Mackay DF, Sattar N, Pell JP. Ethnic-specific obesity cutoffs for diabetes risk: cross-sectional study of 490,288 UK biobank participants. Diabetes Care. 2014;37(9):2500-7.

7. Pradhan AD. Sex differences in the metabolic syndrome: implications for cardiovascular health in women. Clin Chem. 2014;60(1):44-52.

8. Hoenig MR, Cowin G, Buckley R, McHenery C, Coulthard A. Low density lipoprotein cholesterol is inversely correlated with abdominal visceral fat area: a magnetic resonance imaging study. Lipids Health Dis. 2011;10:12.

9. Rashid S, Watanabe T, Sakaue T, Lewis GF. Mechanisms of HDL lowering in insulin resistant, hypertriglyceridemic states: the combined effect of $\mathrm{HDL}$ triglyceride enrichment and elevated hepatic lipase activity. Clin Biochem. 2003;36(6):421-9.

10. Sun J, Zhou W, Gu T, Zhu D, Bi Y. A retrospective study on association between obesity and cardiovascular risk diseases with aging in Chinese adults. Sci Rep. 2018;8(1):5806.

11. Castelli WP, Anderson K, Wilson PW, Levy D. Lipids and risk of coronary heart disease. The Framingham Study. Ann Epidemiol. 1992;2(1-2):23-8.

12. Gordon T, Castelli WP, Hjortland MC, Kannel WB, Dawber TR. High density lipoprotein as a protective factor against coronary heart disease. The Framingham Study. Am J Med. 1977;62(5):707-14.

13. Gupta R, Rastogi P, Sarna M, Gupta VP, Sharma SK, Kothari K. Body-mass index, waist-size, waist-hip ratio and cardiovascular risk factors in urban subjects. J Assoc Physicians India. 2007;55:621-7.

14. Zhang L, Chen S, Deng A, Liu X, Liang Y, Shao X, et al. Association between lipid ratios and insulin resistance in a Chinese population. PLoS One. 2015; 10(1):e0116110.

15. Health, United States, 2010: with special feature on death and dying. Hyattsville: Health, United States. 2011.

16. Kim JK, Alley D, Seeman T, Karlamangla A, Crimmins E. Recent changes in cardiovascular risk factors among women and men. J Women's Health (Larchmt). 2006;15(6):734-46.

17. Nabel EG. Heart disease prevention in young women: sounding an alarm. Circulation. 2015;132(11):989-91.

18. Gudmundsdottir H, Hoieggen A, Stenehjem A, Waldum B, Os I. Hypertension in women: latest findings and clinical implications. Ther Adv Chronic Dis. 2012;3(3):137-46.

19. El Brini O, Akhouayri O, Gamal A, Mesfioui A, Benazzouz B. Prevalence of metabolic syndrome and its components based on a harmonious definition among adults in Morocco. Diabetes Metab Syndr Obes. 2014;7:341-6.

20. Beigh SH, Jain S. Prevalence of metabolic syndrome and gender differences. Bioinformation. 2012:8(13):613-6.

21. Clinical guidelines on the identification, evaluation, and treatment of overweight and obesity in adults: executive summary. Expert Panel on the Identification, Evaluation, and Treatment of Overweight in Adults. Am J Clin Nutr. 1998;68(4): 899-917.

22. Chinedu SN, Ogunlana OO, Azuh DE, Iweala EE, Afolabi IS, Uhuegbu CC, et al. Correlation between body mass index and waist circumference in Nigerian adults: implication as indicators of health status. J Public Health Res. 2013;2(2):e16.

23. Ogden $\mathrm{CL}$, Carroll MD, Fryar CD, Flegal KM. Prevalence of obesity among adults and youth: United States, 2011-2014. NCHS Data Brief. 2015(219):1-8.

24. Yun S, Zhu BP, Black W, Brownson RC. A comparison of national estimates of obesity prevalence from the behavioral risk factor surveillance system and the national health and Nutrition Examination Survey. Int J Obes. 2006;30(1):164-70.

25. Flegal KM, Kruszon-Moran D, Carroll MD, Fryar CD, Ogden CL. Trends in obesity among adults in the United States, 2005 to 2014. JAMA. 2016; 315(21):2284-91.
26. Kramer H, Gutierrez OM, Judd SE, Muntner P, Warnock DG, Tanner RM, et al. Waist circumference, body mass index, and ESRD in the REGARDS (reasons for geographic and racial differences in stroke) study. Am J Kidney Dis. 2016:67(1):62-9.

27. Taylor H, Liu J, Wilson G, Golden SH, Crook E, Brunson CD, et al. Distinct component profiles and high risk among African Americans with metabolic syndrome: the Jackson Heart Study. Diabetes Care. 2008;31(6):1248-53.

28. Kanter R, Caballero B. Global gender disparities in obesity: a review. Adv Nutr. 2012;3(4):491-8.

29. US NCFHS. Health, United States, 2010: with special feature on death and dying: National Center for Health Statistics (US); 2011.

30. Sturm R, Hattori A. Morbid obesity rates continue to rise rapidly in the United States. Int J Obes. 2013:37(6):889-91.

31. Moore JX, Chaudhary N, Akinyemiju T. Metabolic syndrome prevalence by race/ethnicity and sex in the United States, National Health and Nutrition Examination Survey, 1988-2012. Prev Chronic Dis. 2017;14:E24.

32. Jacobsen BK, Aars NA. Changes in waist circumference and the prevalence of abdominal obesity during 1994-2008 - cross-sectional and longitudinal results from two surveys: the Tromso Study. BMC Obes. 2016;3:41.

33. Martin Castellanos A, Cabanas Armesilla MD, Barca Duran FJ, Martin Castellanos P, Gomez Barrado JJ. Obesity and risk of myocardial infarction in a sample of European males. Waist to-hip-ratio presents information bias of the real risk of abdominal obesity. Nutr Hosp. 2017;34(1):88-95.

34. Nardozza Junior A, Szelbracikowski Sdos S, Nardi AC, Almeida JC. Agerelated testosterone decline in a Brazilian cohort of healthy military men. Int Braz J Urol. 2011;37(5):591-7.

35. Rotter I, Ryl A, Grzesiak K, Szylinska A, Pawlukowska W, Lubkowska A, et al. Cross-sectional inverse associations of obesity and fat accumulation indicators with testosterone in non-diabetic aging men. Int J Environ Res Public Health. 2018:15(6):1207.

36. Page ST, Amory JK, Bowman FD, Anawalt BD, Matsumoto AM, Bremner WJ, et al. Exogenous testosterone (T) alone or with finasteride increases physical performance, grip strength, and lean body mass in older men with low serum T. J Clin Endocrinol Metab. 2005;90(3):1502-10.

37. Snyder PJ, Peachey H, Hannoush P, Berlin JA, Loh L, Lenrow DA, et al. Effect of testosterone treatment on body composition and muscle strength in men over 65 years of age. J Clin Endocrinol Metab. 1999;84(8):2647-53.

38. Allan CA, Strauss BJ, Burger HG, Forbes EA, McLachlan RI. Testosterone therapy prevents gain in visceral adipose tissue and loss of skeletal muscle in nonobese aging men. J Clin Endocrinol Metab. 2008:93(1):139-46.

39. Iwasa T, Matsuzaki T, Yiliyasi M, Yano K, Irahara M. The effects of chronic testosterone administration on body weight, food intake, and fat weight were age-dependent. Steroids. 2017;127:18-23.

40. Haffner SM, Karhapaa P, Mykkanen L, Laakso M. Insulin resistance, body fat distribution, and sex hormones in men. Diabetes. 1994:43(2):212-9.

41. Khaw KT, Barrett-Connor E. Lower endogenous androgens predict central adiposity in men. Ann Epidemiol. 1992;2(5):675-82.

42. Tsai EC, Boyko EJ, Leonetti DL, Fujimoto WY. Low serum testosterone leve as a predictor of increased visceral fat in Japanese-American men. Int J Obes Relat Metab Disord. 2000;24(4):485-91.

43. Janssen I, Powell LH, Kazlauskaite R, Dugan SA. Testosterone and visceral fat in midlife women: the Study of women's Health Across the Nation (SWAN) fat patterning study. Obesity (Silver Spring). 2010;18(3):604-10.

44. Ibanez L, Diaz M, Sebastiani G, Marcos MV, Lopez-Bermejo A, de Zegher F. Oral contraception vs insulin sensitization for 18 months in nonobese adolescents with androgen excess: posttreatment differences in C-reactive protein, intima-media thickness, visceral adiposity, insulin sensitivity, and menstrual regularity. J Clin Endocrinol Metab. 2013;98(5):E902-7.

45. Diaz M, Chacon MR, Lopez-Bermejo A, Maymo-Masip E, Salvador C, Vendrell J, et al. Ethinyl estradiol-cyproterone acetate versus low-dose pioglitazoneflutamide-metformin for adolescent girls with androgen excess: divergent effects on CD163, TWEAK receptor, ANGPTL4, and LEPTIN expression in subcutaneous adipose tissue. J Clin Endocrinol Metab. 2012;97(10):3630-8.

46. Fujioka K, Kajita K, Wu Z, Hanamoto T, Ikeda T, Mori I, et al. Dehydroepiandrosterone reduces preadipocyte proliferation via androgen receptor. Am J Physiol Endocrinol Metab. 2012;302(6):E694-704.

47. Lin HY, Xu Q, Yeh S, Wang RS, Sparks JD, Chang C. Insulin and leptin resistance with hyperleptinemia in mice lacking androgen receptor. Diabetes. 2005;54(6):1717-25.

48. Mclnnes KJ, Smith LB, Hunger NI, Saunders PT, Andrew R, Walker BR Deletion of the androgen receptor in adipose tissue in male mice elevates 
retinol binding protein 4 and reveals independent effects on visceral fat mass and on glucose homeostasis. Diabetes. 2012;61(5):1072-81.

49. Ohlsson C, Hammarstedt A, Vandenput L, Saarinen N, Ryberg H, Windahl SH, et al. Increased adipose tissue aromatase activity improves insulin sensitivity and reduces adipose tissue inflammation in male mice. Am J Physiol Endocrinol Metab. 2017;313(4):E450-E62.

50. Bhasin S, Storer TW, Berman N, Yarasheski KE, Clevenger B, Phillips J, et al. Testosterone replacement increases fat-free mass and muscle size in hypogonadal men. J Clin Endocrinol Metab. 1997;82(2):407-13.

51. Snyder PJ, Peachey H, Berlin JA, Hannoush P, Haddad G, Dlewati A, et al. Effects of testosterone replacement in hypogonadal men. J Clin Endocrinol Metab. 2000;85(8):2670-7.

52. Bhasin S, Taylor WE, Singh R, Artaza J, Sinha-Hikim I, Jasuja R, et al. The mechanisms of androgen effects on body composition: mesenchymal pluripotent cell as the target of androgen action. J Gerontol A Biol Sci Med Sci. 2003;58(12):M1103-10.

53. Borrud LG, Flegal KM, Looker AC, Everhart JE, Harris TB, Shepherd JA. Body composition data for individuals 8 years of age and older: U.S. population, 1999-2004. Vital Health Stat. 2010:(250):1-87.

54. Nishida C, Ko GT, Kumanyika S. Body fat distribution and noncommunicable diseases in populations: overview of the 2008 WHO Expert Consultation on Waist Circumference and Waist-Hip Ratio. Eur J Clin Nutr. 2010;64(1):2-5.

55. Enzi G, Gasparo M, Biondetti PR, Fiore D, Semisa M, Zurlo F. Subcutaneous and visceral fat distribution according to sex, age, and overweight, evaluated by computed tomography. Am J Clin Nutr. 1986;44(6):739-46.

56. Jackson AS, Stanforth PR, Gagnon J, Rankinen T, Leon AS, Rao DC, et al. The effect of sex, age and race on estimating percentage body fat from body mass index: the Heritage Family Study. Int J Obes Relat Metab Disord. 2002; 26(6):789-96.

57. Krotkiewski M, Bjorntorp P, Sjostrom L, Smith U. Impact of obesity on metabolism in men and women. Importance of regional adipose tissue distribution. J Clin Invest. 1983;72(3):1150-62.

58. Pardo JM. Massive hypertriglyceridemia complicating estrogen therapy. J Clin Endocrinol Metab. 1997;82(5):1649-50.

59. Munoz J, Derstine A, Gower BA. Fat distribution and insulin sensitivity in postmenopausal women: influence of hormone replacement. Obes Res. 2002;10(6):424-31.

60. Espeland MA, Stefanick ML, Kritz-Silverstein D, Fineberg SE, Waclawiw MA James MK, et al. Effect of postmenopausal hormone therapy on body weight and waist and hip girths. Postmenopausal estrogen-progestin interventions study investigators. J Clin Endocrinol Metab. 1997;82(5):1549-56.

61. Reubinoff BE, Wurtman J, Rojansky N, Adler D, Stein P, Schenker JG, et al, Effects of hormone replacement therapy on weight, body composition, fat distribution, and food intake in early postmenopausal women: a prospective study. Fertil Steril. 1995;64(5):963-8.

62. Trikudanathan S, Pedley A, Massaro JM, Hoffmann U, Seely EW, Murabito JM, et al. Association of female reproductive factors with body composition: the Framingham Heart Study. J Clin Endocrinol Metab. 2013;98(1):236-44.

63. Brown LM, Clegg DJ. Central effects of estradiol in the regulation of food intake, body weight, and adiposity. J Steroid Biochem Mol Biol. 2010;122(1-3):65-73

64. Clegg DJ, Brown LM, Woods SC, Benoit SC. Gonadal hormones determine sensitivity to central leptin and insulin. Diabetes. 2006;55(4):978-87.

65. Gorres BK, Bomhoff GL, Gupte AA, Geiger PC. Altered estrogen receptor expression in skeletal muscle and adipose tissue of female rats fed a highfat diet. J Appl Physiol (1985). 2011;110(4):1046-53.

66. Crandall DL, Busler DE, Novak TJ, Weber RV, Kral JG. Identification of estrogen receptor beta RNA in human breast and abdominal subcutaneous adipose tissue. Biochem Biophys Res Commun. 1998;248(3):523-6.

67. Pedersen SB, Hansen PS, Lund S, Andersen PH, Odgaard A, Richelsen B. Identification of oestrogen receptors and oestrogen receptor mRNA in human adipose tissue. Eur J Clin Investig. 1996;26(4):262-9.

68. Heine PA, Taylor JA, Iwamoto GA, Lubahn DB, Cooke PS. Increased adipose tissue in male and female estrogen receptor-alpha knockout mice. Proc Natl Acad Sci U S A. 2000;97(23):12729-34

69. Davis KE, Neinast MD, Sun K, Skiles WM, Bills JD, Zehr JA, et al. The sexually dimorphic role of adipose and adipocyte estrogen receptors in modulating adipose tissue expansion, inflammation, and fibrosis. Mol Metab. 2013;2(3):227-42.

70. Bluher M. Importance of estrogen receptors in adipose tissue function. Mol Metab. 2013;2(3):130-2
71. Kim SH, Reaven G. Sex differences in insulin resistance and cardiovascular disease risk. J Clin Endocrinol Metab. 2013;98(11):E1716-21.

72. Zitzmann M, Gromoll J, von Eckardstein A, Nieschlag E. The CAG repeat polymorphism in the androgen receptor gene modulates body fat mass and serum concentrations of leptin and insulin in men. Diabetologia. 2003; 46(1):31-9.

73. Saad F, Rohrig G, von Haehling S, Traish A. Testosterone deficiency and testosterone treatment in older men. Gerontology. 2017;63(2):144-56.

74. Magnussen LV, Glintborg D, Hermann P, Hougaard DM, Hojlund K, Andersen M. Effect of testosterone on insulin sensitivity, oxidative metabolism and body composition in aging men with type 2 diabetes on metformin monotherapy. Diabetes Obes Metab. 2016;18(10):980-9.

75. Navarro G, Allard C, Xu W, Mauvais-Jarvis F. The role of androgens in metabolism, obesity, and diabetes in males and females. Obesity (Silver Spring). 2015:23(4):713-9.

76. Gupte AA, Pownall HJ, Hamilton DJ. Estrogen: an emerging regulator of insulin action and mitochondrial function. J Diabetes Res. 2015:2015:916585.

77. Mauvais-Jarvis F. Menopause, estrogens, and glucose homeostasis in women. Adv Exp Med Biol. 2017;1043:217-25.

78. Mauvais-Jarvis F, Manson JE, Stevenson JC, Fonseca VA. Menopausal hormone therapy and type 2 diabetes prevention: evidence, mechanisms, and clinical implications. Endocr Rev. 2017;38(3):173-88.

79. Yeung EH, Zhang C, Mumford SL, Ye A, Trevisan M, Chen L, et al. Longitudinal study of insulin resistance and sex hormones over the menstrual cycle: the BioCycle Study. J Clin Endocrinol Metab. 2010; 95(12):5435-42.

80. Kumagai S, Holmang A, Bjorntorp P. The effects of oestrogen and progesterone on insulin sensitivity in female rats. Acta Physiol Scand. 1993; 149(1):91-7.

81. Wada $T$, Hori S, Sugiyama M, Fujisawa $E$, Nakano $T$, Tsuneki $H$, et al. Progesterone inhibits glucose uptake by affecting diverse steps of insulin signaling in 3T3-L1 adipocytes. Am J Physiol Endocrinol Metab. 2010;298(4):E881-8.

82. Dolan E, Stanton A, Thijs L, Hinedi K, Atkins N, McClory S, et al. Superiority of ambulatory over clinic blood pressure measurement in predicting mortality: the Dublin outcome study. Hypertension. 2005:46(1):156-61.

83. Palatini $P$, Reboldi G, Beilin LJ, Casiglia E, Eguchi K, Imai Y, et al. Added predictive value of night-time blood pressure variability for cardiovascular events and mortality: the Ambulatory Blood Pressure-International Study. Hypertension. 2014;64(3):487-93.

84. Ferrannini E, Natali A, Capaldo B, Lehtovirta M, Jacob S, Yki-Jarvinen H. Insulin resistance, hyperinsulinemia, and blood pressure: role of age and obesity. European Group for the study of Insulin Resistance (EGIR). Hypertension. 1997;30(5):1144-9.

85. Franklin SS, Wong ND. Hypertension and cardiovascular disease: contributions of the Framingham heart study. Glob Heart. 2013;8(1):49-57.

86. Henry SL, Barzel B, Wood-Bradley RJ, Burke SL, Head GA, Armitage JA. Developmental origins of obesity-related hypertension. Clin Exp Pharmacol Physiol. 2012;39(9):799-806.

87. Kannel WB, Zhang T, Garrison RJ. Is obesity-related hypertension less of a cardiovascular risk? The Framingham Study. Am Heart J. 1990;120(5): $1195-201$.

88. Whelton PK, Carey RM, Aronow WS, Casey DE Jr, Collins KJ, Dennison Himmelfarb C, et al. 2017 ACC/AHA/AAPA/ABC/ACPM/AGS/APhA/ASH/ ASPC/NMA/PCNA Guideline for the prevention, detection, evaluation, and management of high blood pressure in adults: a report of the American College of Cardiology/American Heart Association Task Force on Clinical Practice Guidelines. Hypertension. 2018;71(6):e13-e115.

89. Kim JA, Montagnani M, Koh KK, Quon MJ. Reciprocal relationships between insulin resistance and endothelial dysfunction: molecular and pathophysiological mechanisms. Circulation. 2006;113(15):1888-904.

90. Alvarez GE, Ballard TP, Beske SD, Davy KP. Subcutaneous obesity is not associated with sympathetic neural activation. Am J Physiol Heart Circ Physiol. 2004;287(1):H414-8.

91. Alvarez GE, Beske SD, Ballard TP, Davy KP. Sympathetic neural activation in visceral obesity. Circulation. 2002;106(20):2533-6.

92. Jones PP, Davy KP, Alexander S, Seals DR. Age-related increase in muscle sympathetic nerve activity is associated with abdominal adiposity. Am J Phys. 1997;272(6 Pt 1):E976-80

93. Brooks VL, Shi Z, Holwerda SW, Fadel PJ. Obesity-induced increases in sympathetic nerve activity: sex matters. Auton Neurosci. 2015;187:18-26. 
94. Hogarth AJ, Graham LN, Corrigan JH, Deuchars J, Mary DA, Greenwood JP. Sympathetic nerve hyperactivity and its effect in postmenopausal women. J Hypertens. 2011;29(11):2167-75.

95. Esler M, Hastings J, Lambert G, Kaye D, Jennings G, Seals DR. The influence of aging on the human sympathetic nervous system and brain norepinephrine turnover. Am J Phys Regul Integr Comp Phys. 2002;282(3): R909-16.

96. Matsukawa T, Sugiyama Y, Watanabe T, Kobayashi F, Mano T. Gender difference in age-related changes in muscle sympathetic nerve activity in healthy subjects. Am J Phys. 1998;275(5 Pt 2):R1600-4.

97. Wilsgaard T, Schirmer H, Arnesen E. Impact of body weight on blood pressure with a focus on sex differences: the Tromso Study, 1986-1995. Arch Intern Med. 2000;160(18):2847-53.

98. Lima R, Wofford M, Reckelhoff JF. Hypertension in postmenopausal women. Curr Hypertens Rep. 2012;14(3):254-60.

99. Sowers JR. Diabetes mellitus and cardiovascular disease in women. Arch Intern Med. 1998;158(6):617-21.

100. Khosla N, Kalaitzidis R, Bakris GL. Predictors of hyperkalemia risk following hypertension control with aldosterone blockade. Am J Nephrol. 2009;30(5):418-24.

101. Goodfriend TL, Kelley DE, Goodpaster BH, Winters SJ. Visceral obesity and insulin resistance are associated with plasma aldosterone levels in women. Obes Res. 1999:7(4):355-62.

102. Huby AC, Antonova G, Groenendyk J, Gomez-Sanchez CE, Bollag WB, Filosa $J A$, et al. Adipocyte-derived hormone leptin is a direct regulator of aldosterone secretion, which promotes endothelial dysfunction and cardiac fibrosis. Circulation. 2015;132(22):2134-45.

103. Huby AC, Otvos L Jr, Belin de Chantemele EJ. Leptin induces hypertension and endothelial dysfunction via aldosterone-dependent mechanisms in obese female mice. Hypertension. 2016;67(5):1020-8.

104. Faulkner $\mathrm{J}$, Belin de Chantemele EJ. Sex differences in mechanisms of hypertension associated with obesity. Hypertension. 2018;71(1):15-21.

105. Faulkner JL, Bruder-Nascimento T, Belin de Chantemele EJ. The regulation of aldosterone secretion by leptin: implications in obesity-related cardiovascular disease. Curr Opin Nephrol Hypertens. 2018;27(2):63-9.

106. Chen X, McClusky R, Chen J, Beaven SW, Tontonoz P, Arnold AP, et al. The number of $x$ chromosomes causes sex differences in adiposity in mice. PLoS Genet. 2012:8(5):e1002709.

107. Ji H, Zheng W, Wu X, Liu J, Ecelbarger CM, Watkins R, et al. Sex chromosome effects unmasked in angiotensin II-induced hypertension. Hypertension. 2010;55(5):1275-82.

108. Manson JE, Hsia J, Johnson KC, Rossouw JE, Assaf AR, Lasser NL, et al. Estrogen plus progestin and the risk of coronary heart disease. N Engl J Med. 2003;349(6):523-34

109. Rossouw JE, Anderson GL, Prentice RL, LaCroix AZ, Kooperberg C, Stefanick $\mathrm{ML}$, et al. Risks and benefits of estrogen plus progestin in healthy postmenopausal women: principal results from the Women's Health Initiative randomized controlled trial. JAMA. 2002;288(3):321-33.

110. Miller VM, Manson JE. Women's Health Initiative hormone therapy trials: new insights on cardiovascular disease from additional years of follow up. Curr Cardiovasc Risk Rep. 2013;7(3):196-202.

111. Meyer $\mathrm{H}$, Brown TN, Herman JL, Reisner SL, Bockting WO. Demographic characteristics and health status of transgender adults in select US regions: Behavioral Risk Factor Surveillance System, 2014. Am J Public Health. 2017; 107(4):582-9.

112. Dhejne $C$, Lichtenstein $P$, Boman $M$, Johansson $A L$, Langstrom $N$, Landen $M$. Long-term follow-up of transsexual persons undergoing sex reassignment surgery: cohort study in Sweden. PLoS One. 2011;6(2):e16885.

113. Asscheman H, Giltay EJ, Megens JA, de Ronde WP, van Trotsenburg MA, Gooren LJ. A long-term follow-up study of mortality in transsexuals receiving treatment with cross-sex hormones. Eur J Endocrinol. 2011; 164(4):635-42

114. Irwig MS. Cardiovascular health in transgender people. Rev Endocr Metab Disord. 2018;19(3):243-51.

115. Kidd JD, Dolezal C, Bockting WO. The relationship between tobacco use and legal document gender-marker change, hormone use, and genderaffirming surgery in a United States sample of trans-feminine and transmasculine individuals: implications for cardiovascular health. LGBT Health. 2018;5(7):401-11.

116. Wiik A, Andersson DP, Brismar TB, Chanpen S, Dhejne C, Ekstrom TJ, et al. Metabolic and functional changes in transgender individuals following cross-sex hormone treatment: design and methods of the GEnder Dysphoria Treatment in Sweden (GETS) study. Contemp Clin Trials Commun. 2018;10:148-53.

\section{Publisher's Note}

Springer Nature remains neutral with regard to jurisdictional claims in published maps and institutional affiliations.
Ready to submit your research? Choose BMC and benefit from:

- fast, convenient online submission

- thorough peer review by experienced researchers in your field

- rapid publication on acceptance

- support for research data, including large and complex data types

- gold Open Access which fosters wider collaboration and increased citations

- maximum visibility for your research: over $100 \mathrm{M}$ website views per year

At BMC, research is always in progress.

Learn more biomedcentral.com/submissions 